\title{
RESEARCH
}

\section{Chromosome Map at 75-kb STS Resolution, Revealing Extremes of Recombination and GC Content}

\author{
Ramaiah Nagaraja, Sandra MacMillan, Juha Kere, Carmela Jones, \\ Stephanie Griffin, Matthew Schmatz, Jennifer Terrell, \\ Michael Shomaker, Christopher Jermak, Christian Hott, \\ Mochubeloa Masisi, Steven Mumm, Anand Srivastava, Giuseppe Pilia, \\ Terence Featherstone, Richard Mazzarella, Sheila Kesterson, \\ Brigid McCauley, Brian Railey, Frank Burough, Volker Nowotny, \\ Michele D'Urso, David States, Bernard Brownstein, and \\ David Schlessinger $^{1}$
}

Center for Genetics in Medicine, Washington University School of Medicine, St. Louis, Missouri 63110

\begin{abstract}
A YAC/STS map of the $X$ chromosome has reached an inter-STS resolution of $75 \mathrm{~kb}$. The map density is sufficient to provide YACs or other large-insert clones that are cross-validated as sequencing substrates across the chromosome. Marker density also permits estimates of regional gene content and a detailed comparison of genetic and physical map distances. Five regions are detected with relatively high $G+C$, correlated with gene richness; and a 17-Mb region with very low recombination is revealed between the Xq13.3 (XIST) and Xq21.3 XY homology loci.
\end{abstract}

[The STSs and YACs can be accessed at http:/ /genome.wustl.edu/cgm/cgm.html/.]

In addition to sustaining an exponentially increasing rate of gene finding (Collins 1995), yeast artificial chromosome/sequence-tagged site (STS/YAC)based maps (Burke et al. 1987; Olson et al. 1989) have begun to reveal additional features of chromosome structure and dynamics. For example, during the development of maps for subportions of the $\mathrm{X}$ chromosome, the existence of a second "pseudoautosomal" region at the Xq terminus of the chromosome was demonstrated (Freije and Schlessinger 1992; Freije et al. 1992; Li and Hamer 1995), followed by the discovery that the region shows a unique phenomenon of gene inactivation on both the $X$ and $Y$ homologs (D'Esposito et al. 1996). In another instance, it was shown that a cluster of genes in a delimited segment of Xp11 escape X inactivation (Miller et al. 1995). As the density of markers across the chromosome has increased beyond the $100-\mathrm{kb}$ resolution goal suggested for the

Torresponding author.

E-MAIL davids@sequencer.wustl.edu; FAX (314) 362-3203. "genome initiative," additional features are revealed, as described here.

The average inter-STS distance of $\sim 75 \mathrm{~kb}$ has been achieved by the placement of 2091 STSs on cognate YACs across the $160 \mathrm{Mb}$ of the chromosome. Collectively, the STSs sample $\sim 1 \%$ of $\mathrm{X}$ specific sequences. About half of the STSs (962) are made from YAC insert ends (Kere et al. 1992), and another 592 are from randomly derived unique Xchromosomal sequences. However, the STSs also include 97 expressed sequence tags (ESTs) and 190 gene-specific STSs from known genes, as well as 192 dinucleotide and 38 tri- and tetranucleotide repeat markers that detect polymorphism. As a result, the YAC/STS map can be integrated with transcriptional and genetic maps.

\section{RESULTS}

\section{Mapping Strategy and Performance}

We used a modified "all-walking" form of STS content mapping (Kere et al. 1992) in which STSs were 
derived systematically from YAC insert ends at the edges of contigs to ensure that subsequent screening of YAC libraries would move progressively into new territory. From the screening results, SEGMAP (see Methods) efficiently generates the most probable orders of clones and STSs, and the likely size of current contigs.

Based on simulations, we expected that an essentially complete map should have been assembled after $\sim 600$ screenings; instead, $>1500$ were required. One of the unexpected factors that increased the effort was the smaller size and fourfold higher chimera frequency than had been estimated previously for some YAC collections (for review, see Nagaraja et al. 1994). Also, the amount of insert ends that yielded STSs was lower than anticipated, because $>60 \%$ were either cocloned sequences from other chromosomes, contained repetitive sequence elements, or had a nucleotide composition too high in A and T for STS development. Nevertheless, the intuitive strength of STS content mapping to achieve map closure was realized in the final year of mapping, with a drop in the number of contigs from 120 to 13.

\section{Map Features}

The 2091 STSs are aligned and ordered in 5423 YACs (see Methods) across the $\mathrm{X}$ chromosome (excluding the $3-\mathrm{Mb}$ centromeric region, which remains unmapped). The DNA contents of the YACs have all been estimated to be $\pm 10 \%$ by pulsed-field gel electrophoresis (PFGE) compared to the size of yeast chromosomes (Goffeau et al. 1996), and provide an average of 10 -fold clone coverage of each STS on the chromosome.

In Figure 1, which is a photograph of a WEB representation, parallel vertical components show the following. (1) An ideogram of the chromosome with approximate cytogenetic band positions. (2) The Centre d'Etude du Polymorphisme Humain (CEPH)/Genethon 198.1-cM genetic linkage map (Dib et al. 1996) normalized to the same overall length as the $160-\mathrm{Mb}$ physical map (with its own index scale farther right). (3) Lines joining the corresponding positions of dinucleotide repeat markers that are placed on both the physical and genetic linkage maps; crossed lines indicate discordances, which are usually minor. (4) Boxed cohorts of ordered STSs in 10-Mb intervals from Xpter to Xqter; polymorphic $(\mathrm{CA})_{n}$ markers, genes, and ESTs are color-coded (see Methods and Fig. 1 legend).

The current map is based on a composite interactive assembly of contigs made completely in the Center for Genetics in Medicine or developed in col- laboration with other groups (displayed on a World Wide Web page and published in some cases; see Methods and Acknowledgments). The 13 remaining YAC contigs range from 1.5 to $52 \mathrm{Mb}$ in size, with an average of $12 \mathrm{Mb}$ (the contigs are listed with their marker limits in Methods).

During the construction of the map, YAC sizes and STS content were used in SEGMAP to estimate the minimum, maximum, and average size of nascent contigs. As STS content increased, the three size estimates converged; and by the time $100-\mathrm{kb}$ inter-STS distances were approached, the sizes of contigs were in close agreement with sizes from other sources. For example, the extent of contigs was the same when assessed by rare-cutter restriction enzyme mapping in PFGE for regions of up to 8 Mb in Xp22 (Trump et al. 1996), Xq26 (Pilia et al. 1996), Xq27 (Zucchi et al. 1996), and Xq28 (Palmieri et al. 1994). Also, the total sum of successive contigs is within $5 \%$ of the $160-\mathrm{Mb}$ content of the $\mathrm{X}$ chromosome estimated from cell-sorting experiments (Trask et al. 1990); and the contigs in Xq24qter add up to about one-third the total, or about the cytogenetic fraction of the $X$ included in the X3000.11 cell line containing that region (Nagaraja et al. 1994 and references therein). Thus, the index positions assigned to STSs along the chromosome provide a reasonable first approximation of position and can guide the allocation of regions of known size for long-range sequencing projects (Seventh $\mathrm{X}$ Chromosome Workshop 1996, unpubl. report).

Fewer than 20 of 2400 STSs tested thus far fail to find cognate YACs in the screening of 15 genomic DNA equivalents in YACs, suggesting that the map covers $>99 \%$ of the chromosome. Some of the remaining apparent gaps are still being filled by ongoing screening. Furthermore, in two cases analyzed in Xq28 (Palmieri et al. 1994; Rogner et al. 1994; M. D'Urso, in prep.), DNA gaps in contigs were only on the order of $10-20 \mathrm{~kb}$. Thus, any small amount of uncloned DNA may well be recoverable by longrange PCR amplification from chromosomal DNA preparations.

\section{DISCUSSION}

\section{Universality of the Map}

The internal consistency of the YAC/STS map in clones derived from seven different libraries of human DNA is in accord with the anticipated generality of the structure of the $\mathrm{X}$ chromosome in human populations. As expected, the cohort of STSs present in a region proximal or distal to a translocation 


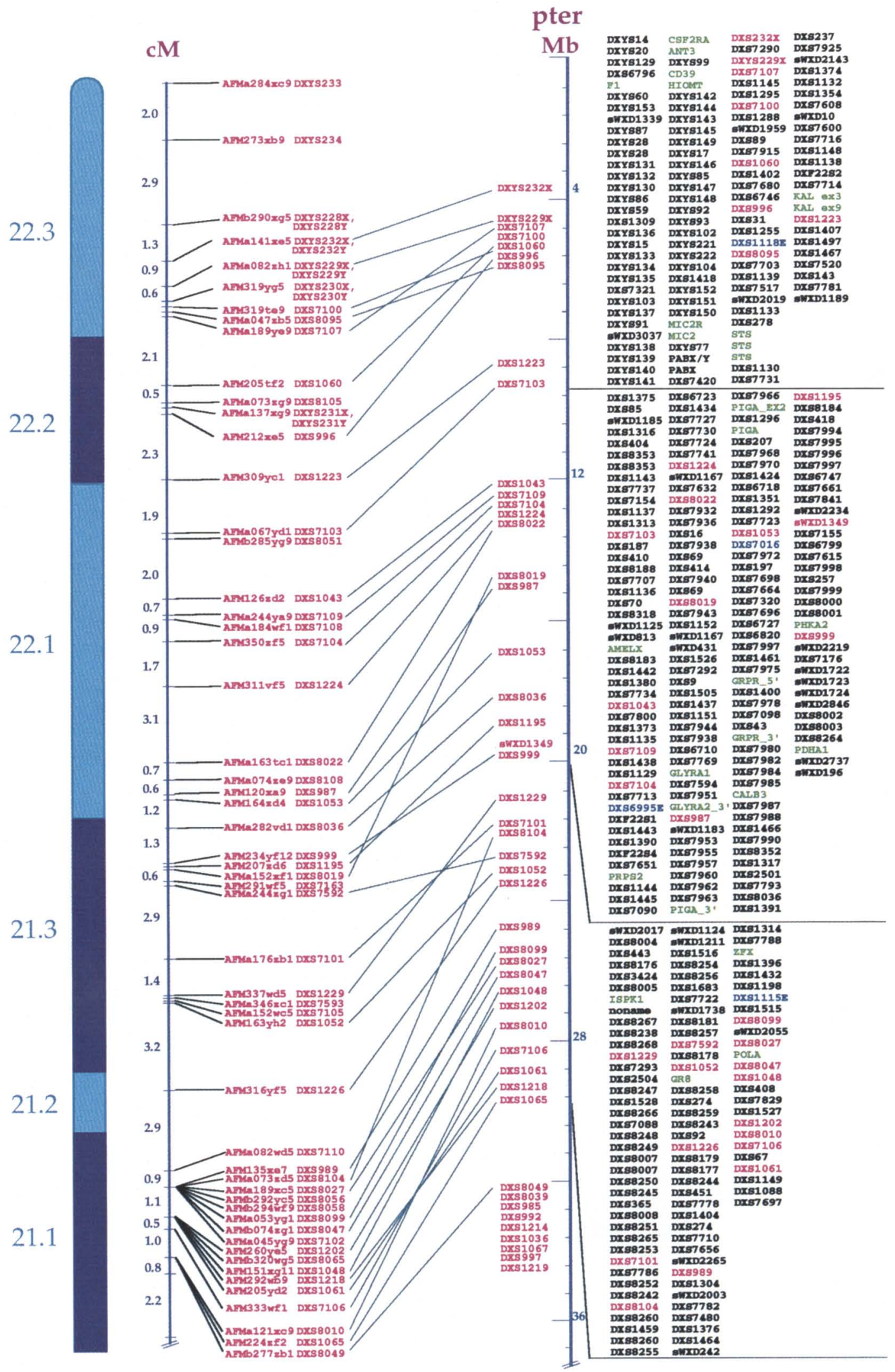

Figure 1 (See page 217 for legend.) 


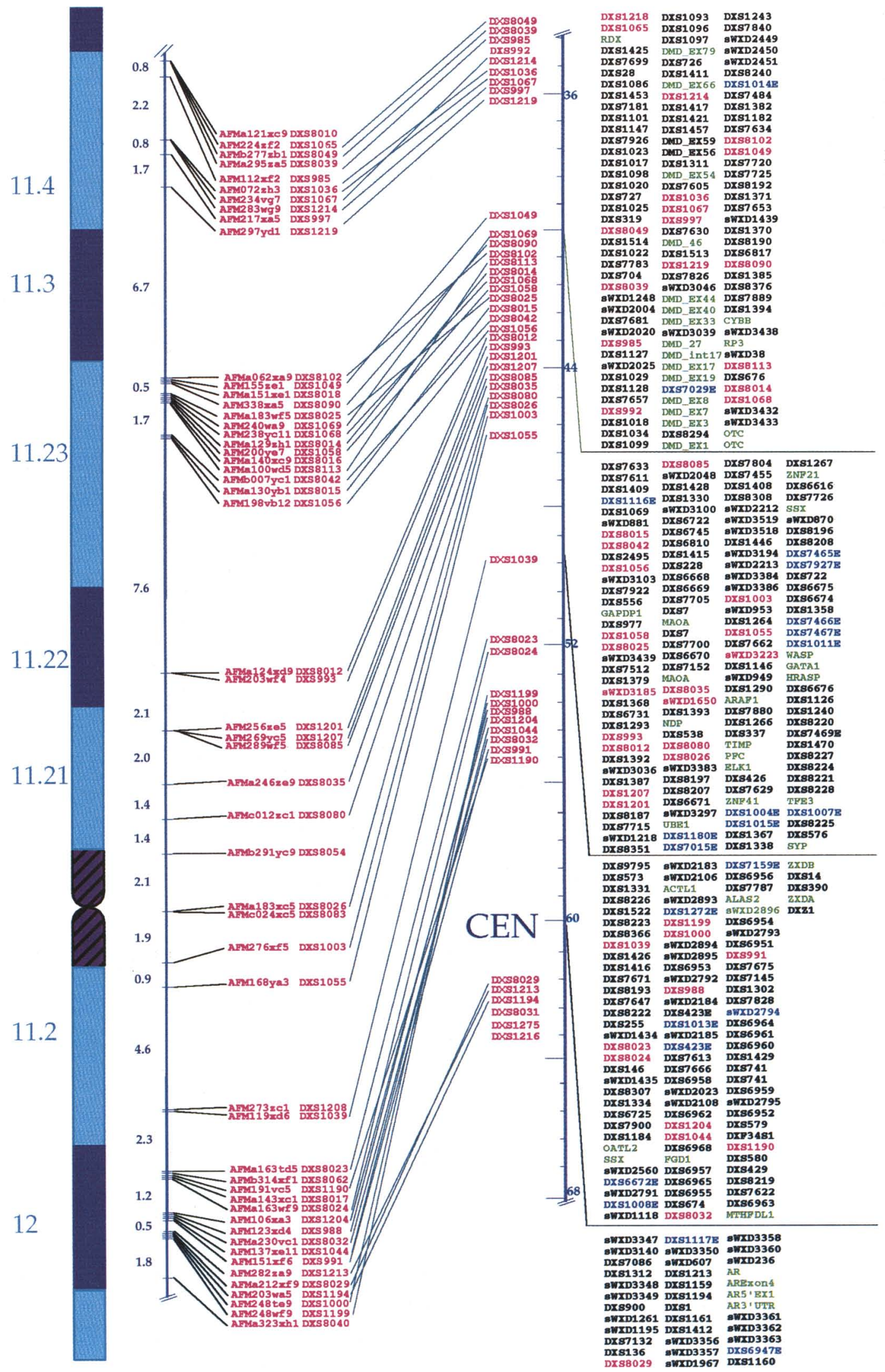

Figure 1 (Continued) 
NAGARAJA ET AL.

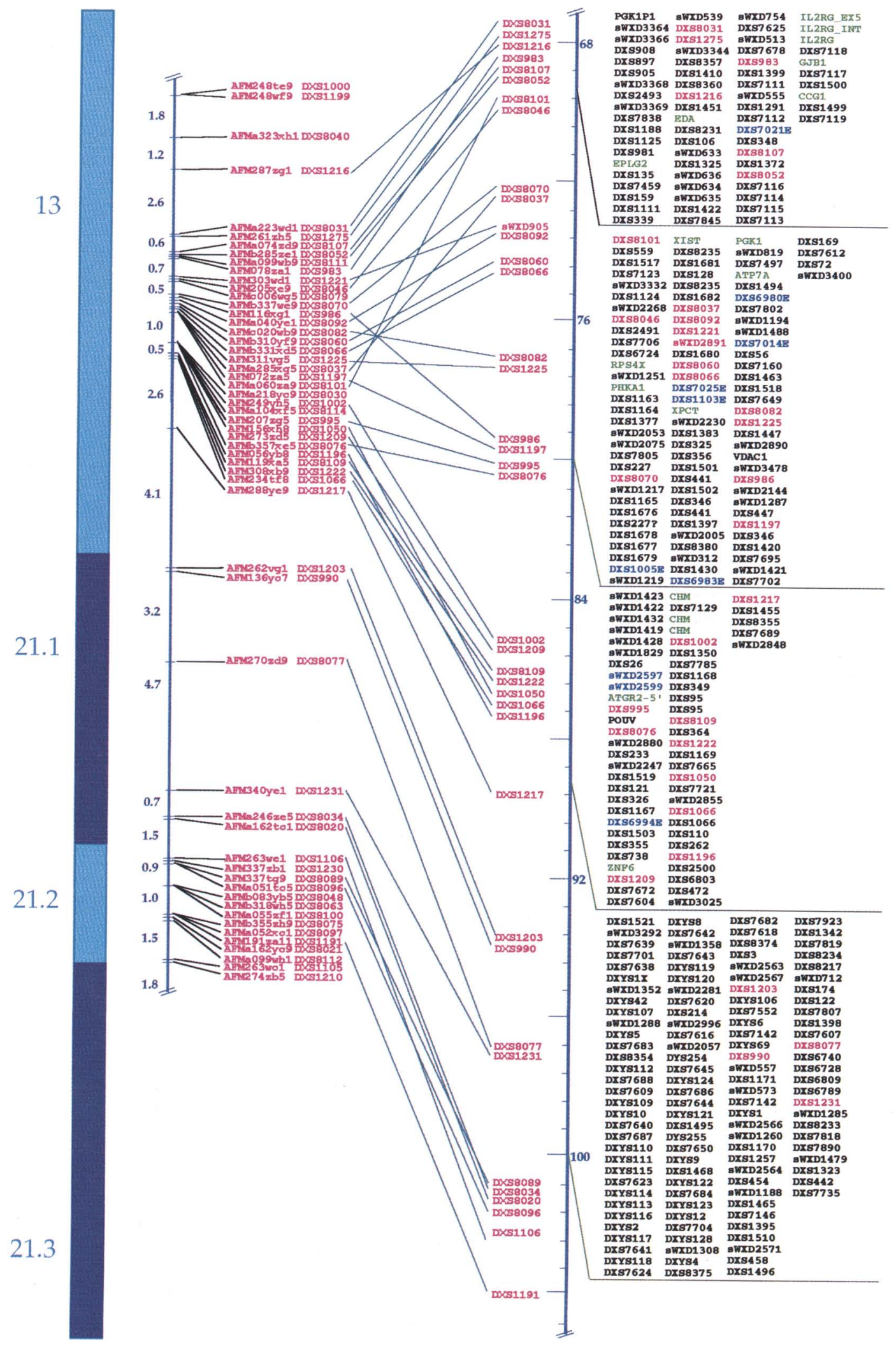

Figure 1 (Continued) 


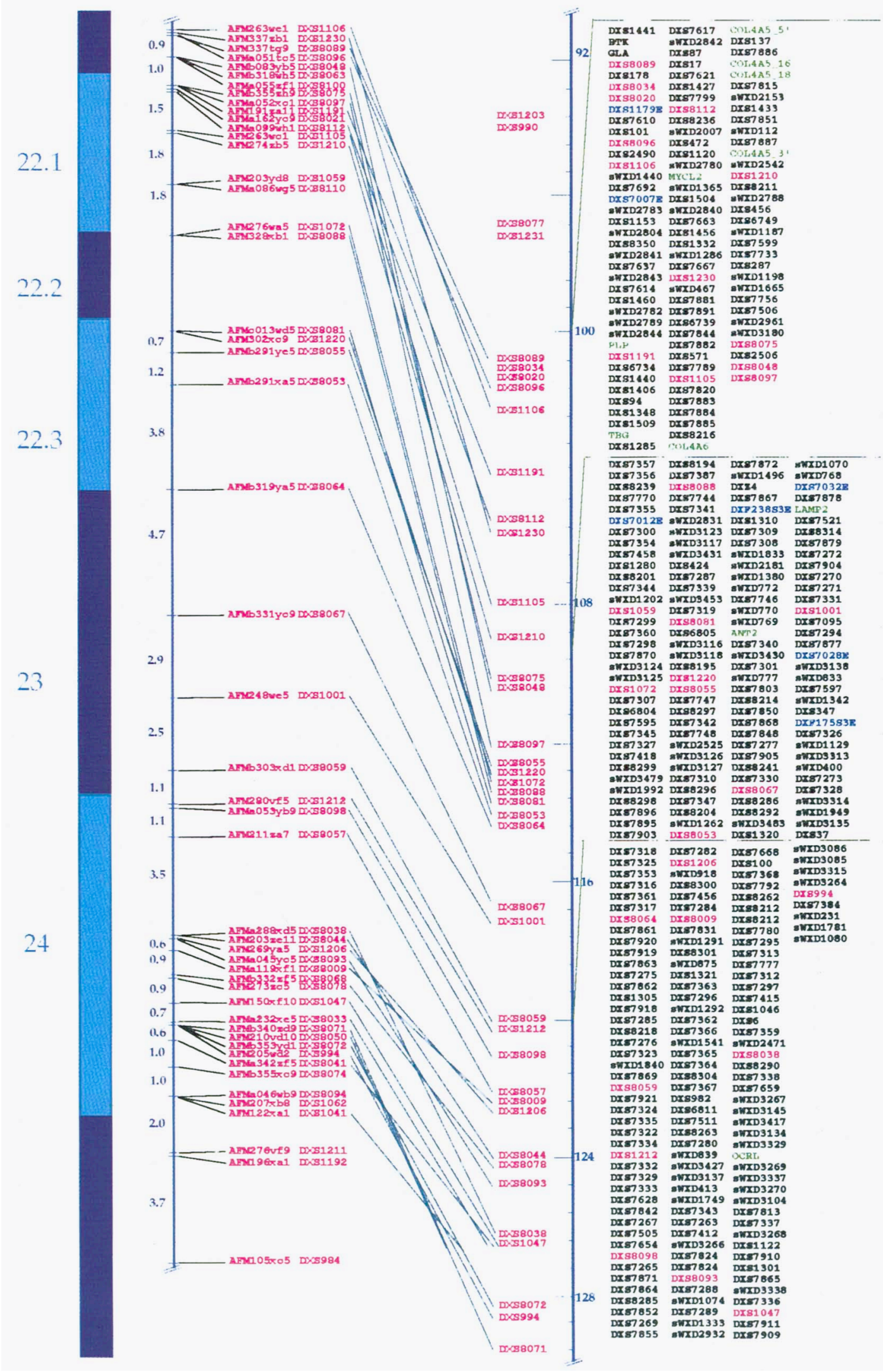

Figure 1 (Continued) 
NAGARAJA ET AL.

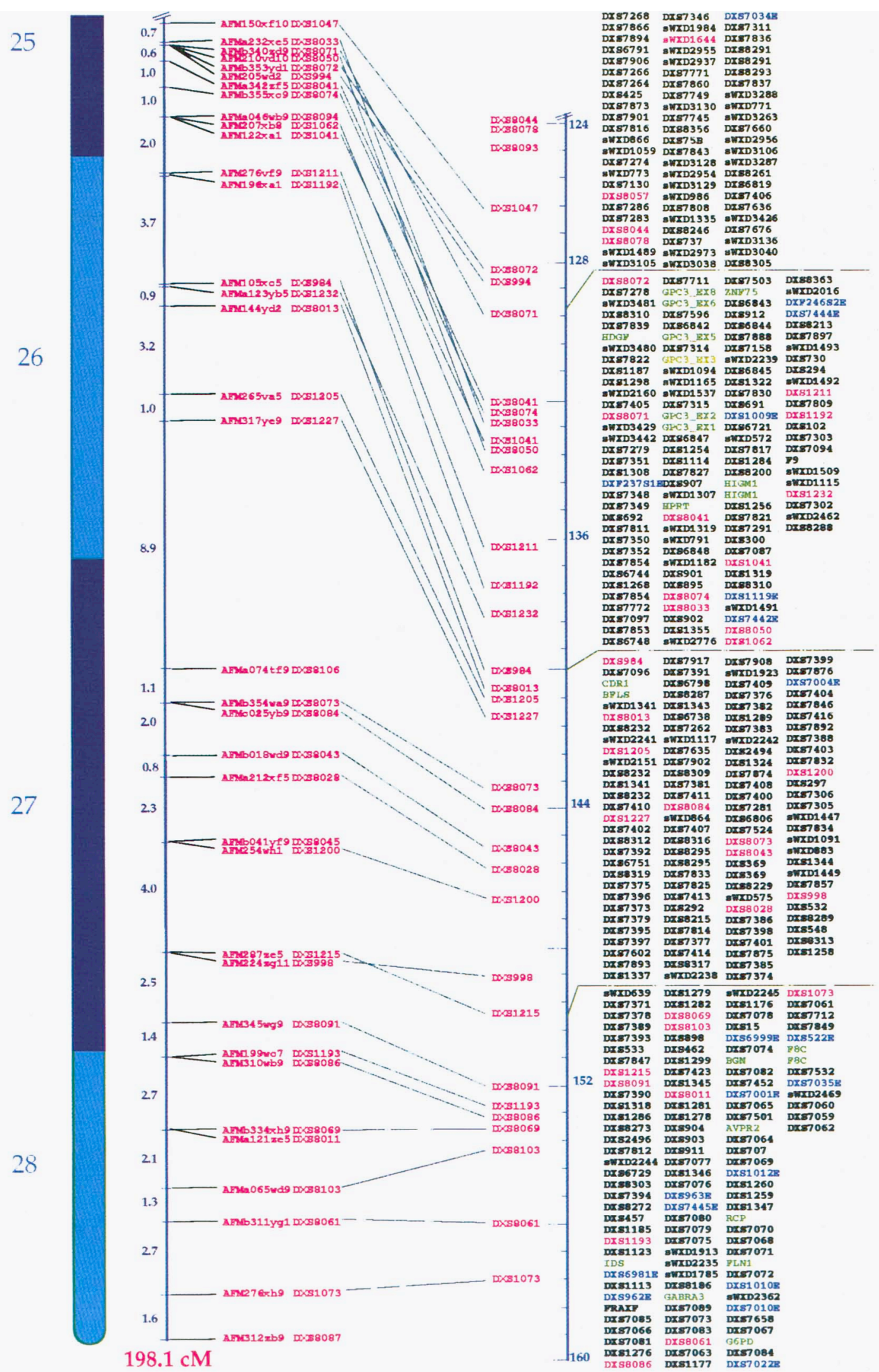

Figure 1 (See facing page for legend). 


\section{CHROMOSOME YAC/STS MAP}

breakpoint or missing in particular deletions (e.g., in Xp22; Ferrero et al. 1995) are consistently found in a contiguous group in the inferred ordered list of STSs of Figure 1. As another example, YACs yWXD1 to yWXD829 in Xq24-qter, derived from an African American, show the same intrinsic content of STSs seen in the region in other YACs, derived from Caucasians.

Overall, the results also support the fidelity of human DNA sequences cloned into YACs. For example, in a contig in Xp22.1 (Trump et al. 1996), 54 STSs were ordered across $3.5 \mathrm{Mb}$ by their content in 58 YACs from five collections. The resulting map showed that an STS was negative at a site between two others in only 4 of 400 instances, consistent with $99 \%$ faithful recovery of $X$ unique sequences.

At the average 75-kb marker density, the essentially universal set of STSs are sufficient not only to evaluate clone quality, but also to screen for alternative large-insert clones, such as bacterial artificial chromosomes (BACs; Shizuya et al. 1992), as sequencing substrates. In initial pilot work, for example, STS-based screening easily recovered minimal tiling paths of overlapping BACS for five projects of at least $1 \mathrm{Mb}$.

\section{Recombination Indices Compared to Location}

Overlapping sets of STSs and clones are sufficient to permit comparisons to other maps. These include partial physical maps assembled at lower resolution and with less than one-third the number of markers, using only mega-YACs, somatic cell hybrid panels, or hybridization or radiation hybrid-based methods (e.g., Chumakov et al. 1995; Roest Crollius et al. 1996). Figure 2 gives an example of possible special interest to human geneticists. Based on the parallel map representations in Figure 1 of the YAC/STS scale and the complete genetic linkage map of Dib et al. (1996), the ratio of genetic to physical distance is plotted in Figure 2 as a cumulative curve showing the integrated sum of $\mathrm{cM} / \mathrm{Mb}$ starting from the $\mathrm{Xp}$ terminus. The overall average of $1.3 \mathrm{cM} / \mathrm{Mb}$ (Dib et al. 1996) is clear, but the ratio varies considerably. An extensive region of very low recombination (B in Fig. 2) is especially striking. Between DXS8046 and DXS1196, a distance of $\sim 16.8 \mathrm{Mb}$, only $2.7 \mathrm{cM}$ in-

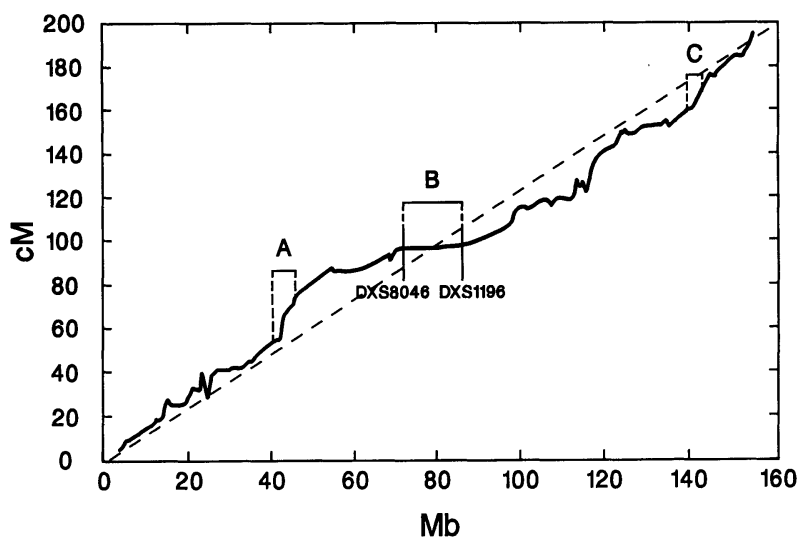

Figure 2 Cumulative $\mathrm{cM}$ vs. Mb distances across the $X$ chromosome. Distances in $\mathrm{CM}$ between successive markers that detect polymorphism are summed and plotted against the corresponding distances in $\mathrm{Mb}$ ( $\mathrm{ab}$ scissa) from Xpter to Xqter. The broken line is drawn with the average (overall) slope of $1.3 \mathrm{cM} / \mathrm{Mb}$. $A$ and $C$ delimit two regions of possible hot spots for recombination; $B$ is a region that shows very low recombination (see text).

tervene, or a ratio of $0.16 \mathrm{cM} / \mathrm{Mb}$. Unexpectedly, this region does not fall at the centromere, where an anticipated but slightly less marked inhibition of recombination is observed (at $\sim 62 \mathrm{Mb}$ on the index scale). Instead, this zone is distinctly more distal, roughly at the center of mass of the chromosome. It begins at or very near the X-inactivation center of the chromosome, the XIST locus (Lyon 1992) and extends distally to another distinctive region that has been delineated by the map, $\sim 4 \mathrm{Mb}$ of DNA homologous on the $\mathrm{X}$ and $\mathrm{Y}$ chromosomes (Sargent et al. 1996).

The conjunction of the XIST locus, with one edge of an extensive region of low recombination, is suggestive. Possibly the involvement of this portion of the chromosome in Barr body formation and global transcriptional regulation may inhibit local synapsis.

The overall average requires that there be regions of higher recombination to compensate for the "cold" region. Two such possible regions are A in $\mathrm{Xp}$ and $\mathrm{C}$ near the Xq26-27 border (Pilia et al.

Figure 1 The STS map compared to the genetic map. Shown is the order of 2091 STSs along the X chromosome, with positions indexed to an approximate scale in megabases. The ideogram of the cytogenetic band pattern is also shown, and the comparative genetic distances (from Dib et al. 1996) are indicated with the 198.1-cM total scaled to the same overall length as the physical map of $160 \mathrm{Mb}$. Mapped markers that detect polymorphism are shown in bright pink between these scales; (Right) Ordered STSs in 10-Mb cohorts also show ESTs in blue, genes in green, and GDB DXS numbers (or sWXD Center designations for those in the submission process) in black. Further updates of marker lists will be posted on the World Wide Web site (see Methods). 


\section{NAGARAJA ET AL.}

1996; Zucchi et al. 1996), with apparent local values of recombination as high as $5 \mathrm{cM} / \mathrm{Mb}$. (A third possible region of high recombination is seen at 115$120 \mathrm{Mb}$ but falls in a region with relatively few genetic markers.)

Regional recombination values can have a considerable impact on searches for disease genes. For example, a translocation breakpoint associated with premature ovarian failure was localized between PGK1 and DXS447 (Powell et al. 1994), a distance of $0.1 \mathrm{cM}$; however, those markers fall in the region with very low recombination values and are $>1 \mathrm{Mb}$ apart on the chromosome. In general, the physical map and recombination-based map agree in marker order where distances are appreciable on both maps; and the physical map provides further ordering information for genetic markers in the regions where recombination values are very low.

\section{Estimate of Gene Concentration by GC Levels in STSs}

The STSs also provide a measure of local gene con- centration. STSs made from mRNA sequences are direct indicators of the location of genes, but at present only $\sim 300$ have been mapped on the X. An alternative measure of regional gene concentration is provided by the relative content of GC in DNA segments. As suggested originally by Bernardi (1993) and confirmed for Xq26-qter (Pilia et al. 1993) and 22q (Gardiner et al. 1993), segments of chromosomal DNA spanning up to $1 \mathrm{Mb}$ or more have characteristic GC contents, and the concentration of the genes is a function of GC. Because the nucleotide compositions of the STSs themselves provide a sampling of GC content, their GC content can be plotted to obtain a profile of GC levels and corresponding putative relative gene concentration across the $\mathrm{X}$. Figure 3 shows the resultant distribution. The middle line and its associated dots show the average GC content of STS sequences in a moving window of groups of 80 . The thinner lines above and below give the $95 \%$ and $5 \%$ confidence limits, respectively, of the estimated GC levels.

Five regions of relatively high ambient GC are seen: one at $\sim 20 \mathrm{Mb}$, two on either side of the cen-

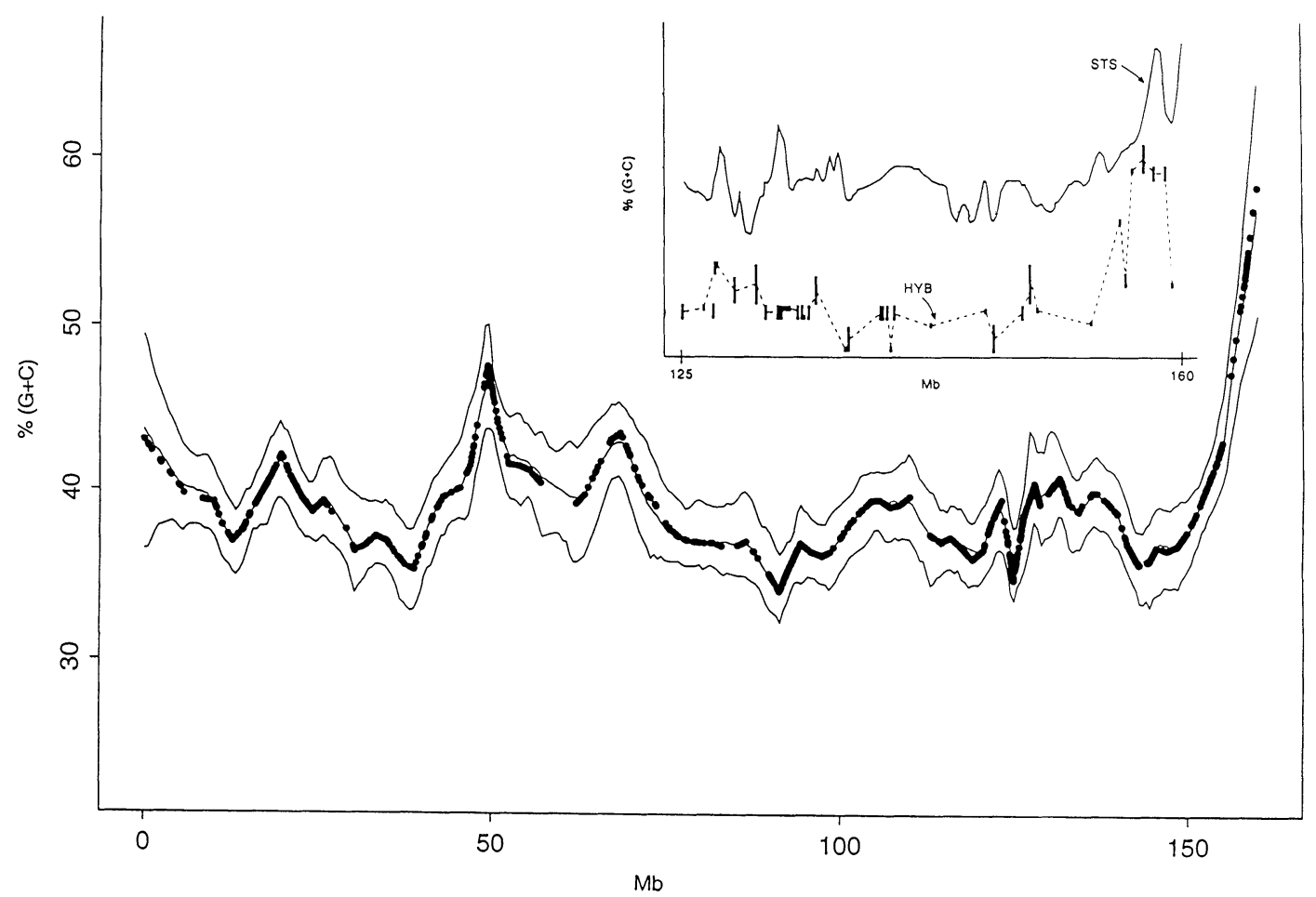

Figure $3 G C$ content across the chromosome estimated by $\%(G+C)$ in the sequences of sets of STSs derived from corresponding locations in the YAC/STS contig map. The curve showing the experimental points found by a sliding window of 80 STSs is accompanied by higher and lower curves representing $95 \%$ and $5 \%$ confidence intervals (see text). (Inset) An enlarged view of the curve between 125 and $160 \mathrm{Mb}$ compared to the GC content of regions estimated with probes on Southern blots of DNA fractionated by density (Pilia et al. 1993). 
tromere, one in Xq26.1, and one, especially marked, rising sharply in subtelomeric Xq28. Two lines of evidence support the validity of these estimates. First, the profile in Xq26 to Xqter strongly resembles that found by an independent assay of GC levels. The inset in Figure 3 compares an enlarged segment of the GC curve from Figure 3 with assays based on Southern analyses with specific probes assayed against DNA fractionated according to its GC content by centrifugation to equilibrium in density gradients (Pilia et al. 1993). The direct assays were done with only a limited number of probes and with localization less precise than that of Fig. 2; but the two inferred distributions are generally concordant. Especially clear is the very high GC level in the Xq subtelomeric region, which has also been confirmed directly by long-range sequencing and other methods (see, for example, Chen et al. 1996).

A second independent line of evidence comes from fluorescent in situ hybridization (FISH) of the highest GC fraction of human DNA (the "H3" isochores; Bernardi 1993) to metaphase chromosomes. Such experiments have detected four of the peaksone in telomeric Xp and three in Xq. High GC segments in the one region undetected by FISH, near the centromere in $\mathrm{Xp}$, have also been demonstrated directly by long-range sequencing (G. Nyakatura, M. Platzer, B. Drescher, H. Hellebrand, D. Schindelhauer, A. Meindl, and A. Rosenthal, pers. comm.). Furthermore, a very similar distribution has begun to emerge from the placement of ESTs along the X chromosome (Schuler et al. 1996). Thus, groups of STSs provide a reliable sample of the GC content of unique sequences in different portions of the $X$.

In the sequencing phase of genome analysis, strategies may be adapted especially for regions of high GC, which tend to show compressions in sequencing and often contain high levels of Alu sequences (Chen et al. 1996), or for regions of low GC, which may contain a number of long, nearly identical LINE sequences (Hood et al. 1995). Similarly, the analysis of regions of high or low GC requires software with differential sensitivity to detect CpG islands or putative exons, and a region that shows low recombination may cue an analysis to look for any correlated "suppressing" sequences. It will be of interest to compare the locations of hot or cold spots of recombination and high or low GC levels on autosomes for which maps reach comparable STS density.

\section{METHODS}

\section{STSs and YACs}

STSs and YACs are described in detail both in the Genome
DataBase (GDB) and on the World Wide Web site at http:// genome.wustl.edu/cgm/cgm.html; STSs that are not yet assigned DXS numbers are identified by their Washington University Genome Center accession (sWXD) numbers. All YACs have been deposited at the American Type Culture Collection (ATCC). Contigs include 5423 YACs from seven libraries (Nagaraja et al. 1994), supplemented with 569 cosmids from the $\mathrm{X}$-specific Lawrence Livermore Laboratory collection and a growing number of BACs, currently totaling 250. The YACs comprise 1360 and 829 clones from two X-specific libraries [F and X3000 (Nagaraja et al. 1994), with an average size of 240 $\mathrm{kb}$; 993 and 1153 clones from two collections made from cell lines containing multiple $\mathrm{X}$ chromosomes ( $\mathrm{E}$ and $\mathrm{I}$, with an average size of $330 \mathrm{~kb}$ ); 290 clones from the CEPH mega-YAC library [(Albertsen et al. 1990), with an average size of 1014 $\mathrm{kb}$, and some additional clones from the Imperial Cancer Research Fund (ICRF) (Larin et al. 1991) and original St. Louis (Nagaraja et al. 1994) YAC libraries.

\section{Strategy and Contigs from STS Content Mapping}

The original formulation of STS content mapping (Green and Olson 1990; Green and Green 1991) was based on initial PCRbased screening of YAC libraries with a series of randomly generated STSs to yield substantial contigs across most of the area of a chromosome. As coverage becomes extensive and new random STSs increasingly fall within already mapped regions, directed walking is initiated with STSs (pseudoends) that map nearest the ends of nascent contigs. In this project, a modified all-walking approach was adopted in which STSs were made from YAC insert ends, and a series of walking steps at many points was then instituted and reiterated (Kere et al. 1992) until contigs merged across the entire $X$ chromosome. This strategy was theoretically more efficient (Palazzolo et al. 1991; Kere et al. 1992) and was facilitated by the availability of two collections of X-specific YACs to initiate STS development and the merger of seed contigs (Nagaraja et al. 1994).

Contigs were aligned and oriented by a combination of FISH (Srivastava et al. 1995) and published marker orders and deletion panels. The somatic cell hybrid panel used hamster cell lines containing an entire X (GM06218C) or defined fragments of X chromosomes [Xp21.2-qter (GM111713); Xp11.2-qter (GM10501); Xq13-qter (GM10095); Xq21.3-qter (GM11172); and Xq24-qter (X3000.1)].

The current 13 contigs, with their bracketing markers, index positions roughly in megabases, and relevant references to some of the significant partial published versions (in addition to Schlessinger et al. 1991 and Nelson et al. 1995), are as follows, from Xpter to Xqter: Xpter-DXS6667 (0-52 Mb; Coffey et al. 1992; Monaco et al. 1992; Alitalo et al. 1995; Black et al. 1995; Ferrero et al. 1995; Ried et al. 1995; Trump et al. 1996; Boycott et al. 1996); OATL2-centromere (52-58.5 Mb; Miller et al. 1995); centromere; DXS62-DXS1 (62-63 Mb); DXS1-DXS1225 (63-79 Mb; Villard et al. 1995); DXS447DXS26 (79-84 Mb; van der Maarel et al. 1995); DXS995-TBG (84-106 Mb; Vetrie et al. 1994; Forbes et al. 1996, Sargent et al. 1996); DXS7667-COL4A5 (107-109.5 Mb; Srivastava et al. 1995); DXS1210-DXS287 (109.5-113 Mb); DXS1059DXS8088 (113-118.5 Mb); DXS7308-DXS7872 (118.5-120 $\mathrm{Mb})$; ANT2-DXS7317 (120-124 Mb); DXS8081-DXS1206 (124-131 Mb); and DXS1339-Xqter (131-160 Mb; Palmieri et al. 1994; Rogner et al. 1994; Pilia et al. 1996; Zucchi et al. 1996). 


\section{NAGARAJA ET AL.}

\section{Use of SEGMAP}

STS content mapping was sustained and directed by the application of the SEGMAP program (developed by C. Magness and P. Green, available from Chuck@chimera.biotech.washington.edu). The most probable marker order was inferred from YAC/STS content (Green and Green 1991) with the program. In the middle game of mapping, contig formation and software representations of maps were very sensitive to false positives, which often joined distant portions of the X chromosome; but these were later sorted out by additional clones and cross-testing of STS content.

SEGMAP also facilitated the integration of outside data, based on the screening of published STSs to identify their location in relation to existing contigs. The comparative localization was extended to infer relative genetic and physical distances, as in Figures 2 and 3.

\section{ACKNOWLEDGMENTS}

We are indebted to many collaborators in the X community for cooperative mapping interactions, including the provision of auxiliary STSs, YACs, and cosmids. Our major collaborators include G. Rappold (XpPAR); G.B. Ferraro, A. Ballabio, D. Nelson, T. Alitalo, and D. Trump (Xp22); K. Boycott and T. BechHansen (Xp11.3-p11.4); A. Miller and H.F. Willard (the pericentromeric region); P. Stanier and F. Cremers (Xq21.3); and especially I. Zucchi, G. Palmieri, G. Romano, and the group of M. D'urso (Xq24-qter); Jean Weissenbach and Jeff Murray (simple sequence repeat markers and genetic map information prior to publication); and GDB (additional STS information). This work was supported by GESTEC (grant HG00201) from the National Center for Genome Research.

The publication costs of this article were defrayed in part by payment of page charges. This article must therefore be hereby marked "advertisement" in accordance with 18 USC section 1734 solely to indicate this fact.

\section{REFERENCES}

Albertsen, H.M., H. Abderrahim, H.M. Cann, J. Dausset, D. LePaslier, and D. Cohen. 1990. Construction and characterization of a yeast artificial chromosome library containing seven haploid human genome equivalents. Proc. Nat. Acad. Sci. 87: 4256-4260.

Alitalo, T., F. Francis, J. Kere, H. Lehrach, D. Schlessinger, and H.F. Willard. 1995. A 6-Mb YAC contig in Xp22.1-p22.2 spanning the DXS69E, XE59, GLRA2, PIGA, GRPR, CALB3, and PHKA2 genes. Genomics 25: 691-700.

Bernardi, G. 1993. The human genome organization and its evolutionary history: A review. Gene 135: 57-66.

Black, G.C.M., M.P. Coleman, Z.Y. Chen, A.H. Nemeth, K.E. Davies, and I.W. Craig. 1995. A bidirectional YAC walk from Norrie disease (NDP) locus. Genomics 25: 644-649.

Boycott, K.M., G.R. Halley, D. Schlessinger, and T. Bech-Hansen. 1996. A 2-megabase physical contig incorporating 43 DNA markers on the human X chromosome at p11.23-p11.22 from ZNF21 to DXS255. Genomics 33: 488-497.

Burke, D.T., G.F. Carle, and M.V. Olson. 1987. Cloning of large segments of exogenous DNA into yeast by means of artificial chromosome vectors. Science 236: 806-812.

Chen, E.Y., M. Zollo, R. Mazzarella, A. Ciccodicola, C. Chen, L. Zuo, C. Heiner, F. Burough, M. Repetto, D. Schlessinger, and M. D'Urso. 1996. Long-range sequence analysis in Xq28: Thirteen known and six candidate genes in $219.4 \mathrm{~kb}$ of high GC DNA between the $R C P / G C P$ and G6PD loci. Hum. Mol. Genet. 5: 659-668.

Chumakov, I.M., P. Rigault, I. Le Gall, C.

Bellanne-Chantelot, A. Billault, S. Guillou, P. Soularue, G. Guasconi, E. Poullier, I. Gros, et al. 1995. A YAC contig map of the human genome. Nature 377: 175-297.

Coffey, A.J., R.G. Roberts, E.D. Green, C.G. Cole, R. Butler, R. Anand, F. Giannelli, and D.R. Bentley. 1992. Construction of a $2.6-\mathrm{Mb}$ contig in yeast artificial chromosomes spanning the human dystrophin gene using an STS-based approach. Genomics 12: 474-484.

Collins, F.S. 1995. Positional cloning moves from perditional to traditional. Nature Genet. 9: 348-350.

D'Esposito, M., A. Ciccodicola, F. Gianfrancesco, T. Esposito, F. Flagiello, R. Mazzarella, D. Schlessinger, and M. D'Urso. 1996. A synaptobrevin-like gene in the Xq28 pseudoautosomal region undergoes $\mathrm{X}$ inactivation. Nature Genet. 13: 227-229.

Dib, C., S. Faure, C. Fizames, D. Samson, N. Drouot, A Vignal, P. Millasseau, S. Marc, J. Hazan, E. Seboun, M. Lathrop, G. Gyapay, J. Morissette, and J. Weissenbach. 1996. A comprehensive genetic map of the human genome based on 5,264 microsatellites. Nature 380: 152-154.

Ferrero, G.B., B. Franco, E.J. Roth, B.A. Firulli, G. Borsani, J. Delmas-Mata, J. Weissenbach, G. Halley, D. Schlessinger, A.C. Chinault, H.Y. Zoghbi, D.L. Nelson, and A. Ballabio. 1995. An integrated physical and genetic map of a $35 \mathrm{Mb}$ region on chromosome Xp22.3-Xp21.3. Hum. Mol. Genet. 4: $1821-1827$.

Forbes, S.A., L. Brennan, M. Richardson, A. Coffey, D.R. Bentley, S. Mumm, G.E. Moore, and P. Stanier. 1996. Refined mapping and YAC contig cloning of the X-linked cleft palate and ankyloglossia locus (CPX) including the proximal X-Y homology breakpoint within Xq21.3. Genomics 31: 36-43.

Freije, D. and D. Schlessinger. 1992. A 1.6-Mb contig of yeast artificial chromosomes around the human factor VIII gene reveals three regions homologous to probes for the DXS115 locus and two for the DXYS64 locus. Am. J. Hum. Genet. 51: 66-80.

Freije, D., C. Helms, M.S. Watson, and H. Donis-Keller. 1992. Identification of a second pseudoautosomal region near the Xq and Yq telomeres. Science 258: 1784-1787. 


\section{CHROMOSOME YAC/STS MAP}

Gardiner, K., B. Aissani, and G. Bernardi. 1993. A compositional map of human chromosome 21. EMBO J. 9: $1853-1858$.

Goffeau, A., B.G. Barrell, H. Bussey, R.W. Davis, B. Dujon, H. Feldmann, F. Galibert, J.D. Hoheisel, C. Jacq, M. Johnston, E.J. Louis, H.W. Mewes, Y. Murakami, P. Philippsen, H. Tettelin, and S.G. Oliver. 1996. Life with 6000 genes. Science 274: 546; 563-567.

Green, E.D. and P. Green. 1991. Sequence-tagged site (STS) content mapping of human chromosomes: Theoretical considerations and early experiences. PCR Methods Applic. 1: 77-90.

Green, E.D. and M.V. Olson. 1990. Chromosomal region of the cystic fibrosis gene in yeast artificial chromosomes: A model for human genome mapping. Science 250: 94-98.

Hood, L., L. Rowen, and B.F. Koop. 1995. Human and mouse T-cell receptor loci: Genomics, evolution, diversity, and serendipity. Ann. N.Y. Acad. Sci. 758: 390-412.

Kere, J., R. Nagaraja, S. Mumm, A. Ciccodicola, M. D’Urso, and D. Schlessinger. 1992. Mapping human chromosomes by walking with sequence-tagged sites from end-fragments of yeast artificial chromosome inserts. Genomics 14: $241-248$.

Larin, Z., A.P. Monaco, and H. Lehrach. 1991. Yeast artificial chromosome libraries containing large inserts from mouse and human DNA. Proc. Natl. Acad. Sci.

88: $4123-4127$.

Li, L. and D.H. Hamer. 1995. Recombination and allelic association in the Xq/Yq homology region. Hum. Mol. Genet. 4: 2013-2016.

Lyon, M.F. 1992. Some milestones in the history of X-chromosome inactivation. Annu. Rev. Genet. 26: 17-28.

Miller, A.P., K. Gustashaw, D.J. Wolff, S.H.J. Rider, A.P. Monaco, B. Eble, D. Schlessinger, J.L. Gorski, G.-J. van Ommen, J. Weissenbach, and H.F. Willard. 1995. Three genes that escape $X$ chromosome inactivation are clustered within a $6 \mathrm{Mb}$ YAC contig and STS map in Xp11.21-p11.22. Hum. Mol. Genet. 4: 731-739.

Monaco, A.P., A.P. Walker, I. Millwood, Z. Larin, and H. Lehrach. 1992. A yeast artificial chromosome contig containing the complete Duchenne muscular dystrophy gene. Genomics 12: 465-473.

Nagaraja, R., J. Kere, S. MacMillan, M.W.J. Masisi, D. Johnson, G. Halley, B.A. Molini, K. Wein, M. Trusgnich, B. Ebel, B.H. Brownstein, B. Railey, and D. Schlessinger. 1994. Characterization of four human YAC libraries for clone size, chimerism, and $\mathrm{X}$ chromosome sequence representation. Nucleic Acids Res. 22: 3406-3411.

Nelson, D.L., A. Ballabio, F. Cremers, A.P. Monaco, and D. Schlessinger. 1995. Report of the sixth international workshop on X chromosome mapping 1995. Cytogenet. Cell Genet. 71: 307-342.
Olson, M.V., L. Hood, C. Cantor, and D. Botstein. 1989. A common language for physical mapping of the human genome. Science 245: 1434-1435.

Palazzolo, M.J., S.A. Sawyer, C.H. Martin, D.A. Smoller, and D.L. Hartl. 1991. Optimized strategies for sequence-tagged-site selection in genome mapping. Proc. Natl. Acad. Sci. 88: 8034-8038.

Palmieri, G., G. Romano, A. Ciccodicola, A. Casamassimi, C. Campanile, T. Esposito, V. Cappa, A. Lania, S. Johnson, R. Reinbold, A. Poustka, D. Schlessinger, and M. D'Urso. 1994. YAC contig organization and CpG island analysis in Xq28. Genomics 24: 149-158.

Pilia, G., R.D. Little, A. Aissani, G. Bernardi, and D. Schlessinger. 1993. Isochores and CpG islands in YAC contigs in human Xq26.1-qter. Genomics 17: 456-562.

Pilia, G., S. MacMillan, R. Nagaraja, S. Mumm, J.

Weissenbach, and D. Schlessinger. 1996. YAC/STS map of 9 $\mathrm{Mb}$ of Xq26 at $100 \mathrm{~kb}$ resolution, localizing 6 ESTs, 5 genes, and 32 genetic markers. Genomics 34: 55-62.

Powell, C.M., R.T. Taggart, T.C. Drumheller, D. Wangsa, C. Qian, L.M. Nelson, and B.J. White. 1994. Molecular and cytogenetic studies of an X; autosome translocation in a patient with premature ovarian failure and review of the literature. Am. J. Med. Genet. 52: 19-26.

Ried, K., A. Mertz, R. Nagaraja, M. Trusgnich, J.H. Riley, A. Anand, H. Lehrach, D. Page, J.W. Ellison, and G. Rappold. 1995. Characterization of a YAC contig spanning the pseudoautosomal region. Genomics 29: 787-792.

Roest Crollius, H., M.T. Ross, A. Grigoriev, C.J. Knights, E. Holloway, J. Misfud, K. Li, M. Playford, S.G. Gregory, S.J. Humphray, A.J. Coffey, C.G. See, S. Marsh, et al. 1996. An integrated map of the human X chromosome. Genome Res. 6: 943-955.

Rogner, U.C., P. Kioschis, K. Wilke, W. Gong, E. Pick, A. Dietrich, U. Zechner, H. Hameister, A. Pragliola, G.E. Herman, et al. 1994. A YAC clone map spanning 7.5 megabases of human chromosome band Xq28. Hum. Mol. Genet. 3: 2137-2146.

Sargent, C.A., H. Briggs, I.J. Chalmers, B. Lambson, E. Walker, and N.A. Affara. 1996. The sequence organization of $\mathrm{Yp}$ /proximal Xq homologous regions of the human sex chromosomes is highly conserved. Genomics 32: 200-209.

Schlessinger, D., R.D. Little, D. Freije, F. Abidi, I. Zucchi, G. Porta, G. Pilia, R. Nagaraja, S.K. Johnson, J.Y. Yoon, A. Srivastava, J. Kere, G. Palmieri, A. Ciccodicola, V. Montanaro, G. Romano, A. Casamassimi, and M. D'Urso. 1991. Yeast artificial chromosome-based genome mapping: Some lessons from Xq24-q28. Genomics 11: 783-793.

Schuler, G.D., M.S. Boguski, E.A. Stewart, L.D. Stein, G. Gyapay, K. Rice, R.E. Whie, P. Rodriguez-Tomé, A.

Aggarwal, E. Bajorek, et al. 1996. A gene map of the human genome. Science 274: 540-546, 547-563. 


\section{NAGARAJA ET AL.}

Shizuya, H., B. Birren, U.J. Kim, V. Mancino, T. Slepak, Y. Tachiiri, and M. Simon. 1992. Cloning and stable maintenance of 300-kilobase-pair fragments of human DNA in Escherichia coli using an F-factor-based vector. Proc. Natl. Acad. Sci. 89: 8794-8797.

Srivastava, A.K., T. Featherstone, K. Wein, and D. Schlessinger. 1995. YAC contigs mapping the human COL4A5 and COL4A6 genes and DXS118 within Xq21.3-q22. Genomics 26: 502-509.

Trask, B., G. van den Engh, R. Nussbaum, C. Schwartz, and J. Gray. 1990. Quantification of the DNA content of structurally abnormal X chromosomes and X chromosome aneuploidy using high resolution bivariate flow karyotyping. Cytometry 11: 184-915.

Trump, D., G. Pilia, P.H. Dixon, C. Wooding, R. Thakkar, S.E.A. Leigh, R. Nagaraja, M.P. Whyte, D. Schlessinger, and R.V. Thakker. 1996. Construction of a YAC contig and an STS map spanning 3.6 megabase pairs in Xp22.1. Human Genet. 97: 60-68.

Van der Maarel, S.M., I.H.J.M. Sholten, J.A. Maat-Kievit, I. Hubber, Y.J.M. de Kok, I. de Wijs, T.J. van de Pol, H. van Bokhoven, J.T. den Dunnen, G.J. van Omman, et al. 1995. Yeast artificial chromosome cloning of the Xq13.3-q21.31 region and fine mapping of a deletion associated with choroideremia and nonspecific mental retardation. Eur. J. Hum. Genet. 3: 207-218.

Vetrie, D., E. Kendall, A. Coffey, S. Hassock, J. Collins, C. Todd, H. Lehrach, M. Bobrow, D.R. Bentley, and A. Harris. 1994. A 6.5 Mb yeast artificial chromosome contig incorporating 33 DNA markers on the human $X$ chromosome at Xq22. Genomics 19: 42-47.

Villard, L., J. Gecz, L. Colleaux, A.M. Lossi, J. Chelly, Y. Ishikawa-Brush, A.P. Monaco, and M. Fontes. 1995. Construction of a YAC contig spanning the Xq13.3 subband. Genomics 26: 115-122.

Zucchi, I., S. Mumm, G. Pilia, S. MacMillan, R. Reinbold, L. Susani, J. Weissenbach, and D. Schlessinger. 1996. YAC/STS map across $12 \mathrm{Mb}$ of Xq27 at $25 \mathrm{~kb}$ resolution, merging Xq26-qter. Genomics 34: 42-54.

Received October 1, 1996; accepted in revised form January 17, 1997. 


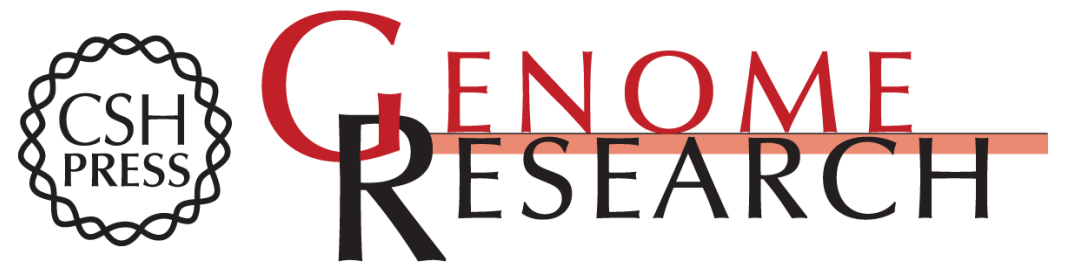

\section{$\mathrm{X}$ chromosome map at 75-kb STS resolution, revealing extremes of recombination and GC content.}

R Nagaraja, S MacMillan, J Kere, et al.

Genome Res. 1997 7: 210-222

Access the most recent version at doi:10.1101/gr.7.3.210

References This article cites 49 articles, 11 of which can be accessed free at:

http://genome.cshlp.org/content/7/3/210.full.html\#ref-list-1

\section{License}

Email Alerting Receive free email alerts when new articles cite this article - sign up in the box at the Service top right corner of the article or click here.

\section{Affordable, Accurate Sequencing.}

To subscribe to Genome Research go to:

https://genome.cshlp.org/subscriptions 